\title{
Coronavirus Disease 2019 (COVID-19) Transmission, Risk Factors, Prevention and Control: A Minireview
}

\author{
Oluwaseun Awosolu ${ }^{1,2^{*}}$ and Oluwole Oladele ${ }^{2}$ \\ ${ }^{1}$ School of Biological Sciences, Universiti Sains Malaysia, Penang, Malaysia \\ ${ }^{2}$ Department of Biology, Federal University of Technology, Akure, Nigeria
}

*Corresponding author: Awosolu Oluwaseun Bunmi, School of Biological Sciences, Universiti Sains Malaysia, 11800 USM, Penang, Malaysia; Department of Biology, Federal University of Technology, Akure, Nigeria

\begin{abstract}
Coronavirus disease 2019 (COVID-19) caused by severe acute respiratory syndrome coronavirus 2 (SARS-CoV-2) which was initially named 2019 novel coronavirus (2019 $\mathrm{nCoV}$ ) have continued to spread at an alarming rate across the globe. It was declared as a pandemic by World Health Organization (WHO) due to its worldwide exponential spread and impact leading to high morbidity and mortality. Generalday-to-day activities was heavily destabilized due to lockdown and Movement Control Order (MCO) policy which are some of the most effective preventive and control measures that were employed by many countries. These measures however eventually had serious detrimental and devastating effect on health, education, governance and economy worldwide. In spite of all the preventive and control measures put in place, COVID-19 continue to spread and ravage many areas of the world. Currently there is still no sufficient, reliable and scientifically sound epidemiological information on COVID-19 transmission dynamic, risk factors, treatment, prevention and control upon which management and containment strategy can be adequately based. Thus, this minireview provides a summary of the transmission, risk factors, prevention and control of COVID-19 disease worldwide.
\end{abstract}

\section{Keywords}

SARS-CoV-2, Coronavirus disease 2019, COVID-19, Disease transmission, Infectious disease, Risk factors

\section{Introduction}

Coronavirus disease 2019 is a highly devastating contagious disease of serious public health concern that is increasingly spreading at an alarming rate in several countries worldwide. It currently remains the deadliest coronavirus in this $21^{\text {st }}$ century [1]. In the first instance, it was named as 2019 novel coronavirus ( $2019 \mathrm{nCoV}$ ) by World Health Organization (WHO). However thereafter, it was renamed and announced as Coronavirus disease 2019 (COVID-19) on $11^{\text {th }}$ February 2020 [2,3]. In the same vein, the International Committee on Taxonomy of Viruses (ICTV) announced the new name of this novel virus as severe acute respiratory syndrome coronavirus 2, SARS-CoV-2 [4]. Currently, the World Health Organization (WHO) has announced this novel coronavirus disease 2019 (COVID-19) to be pandemic infectious disease on March 11, 2020 [2]. The causative organism of this disease is known to be severe acute respiratory syndrome coronavirus 2 (SARS-CoV-2). It belongs to the family Coronaviridae, subfamily Coronavirinae and genus betacoronavirus respectively [5-7]. The coronaviruses are basically classified into alphacoronaviruses, betacoronaviruses, gammacoronaviruses and deltacoronaviruses. Alphacoronaviruses and betacoronaviruses are both infectious and pathogenic to mammals while gammacoronaviruses and deltacoronaviruses majorly infects birds [8-11]. Coronavirus disease 2019 was originally documented in December 2019 from Wuhan, a highly populous, fast-growing capital city of Hubei province which is a central route to many parts of China with different types of transportation means such as buses, cars, trains and airplanes linking many parts of the country $[11,12]$. Obviously, the Whole-genomic sequence of this novel coronavirus infectious disease has proven that it is similar to the two previously recognised coronaviruses which include the Middle East respiratory syndrome (Mers) and severe acute respiratory syn-

Citation: Awosolu O, Oladele O (2020) Coronavirus Disease 2019 (COVID-19) Transmission, Risk Factors, Prevention and Control: A Minireview. J Infect Dis Epidemiol 6:145. doi.org/10.23937/24743658/1510145

Accepted: July 16, 2020: Published: July 18, 2020

Copyright: (c) 2020 Awosolu O, et al. This is an open-access article distributed under the terms of the Creative Commons Attribution License, which permits unrestricted use, distribution, and reproduction in any medium, provided the original author and source are credited. 
drome (Sars) isolated from bat in china [13].

The high transmission capacity of COVID-19 contagious disease have really enhanced the worldwide spread at an alarming rate thereby causing morbidity and mortality which in turn impacted seriously on the national and global economy. As such, WHO have classified risk assessment of COVID-19 as very high [14]. As of Wednesday, 27 th of May 2020 at 01:00 GMT, an estimated worldwide number of deaths have increased to 345,752 and over 5,451,532 cases were recorded in 217 countries and territories [15]. This high transmission has led to closure and lockdown of both public and private organizations worldwide in order to curtail the infectious disease. Therefore, in order to quickly control this COVID-19 health crisis, there is a necessity for enough and updated epidemiological information on infection transmission dynamics, risk factors, prevention and control. This information can subsequently be used to educate the general populace and thereby enhance infection control.

\section{Mode of Transmission}

The major route of transmission of COVID-19 is from person-to-person via respiratory droplets and direct personal and physical contact within the community setting as indicated by currently available evidences [16-21]. This Person-to-person transmission route can be through respiratory droplets which can be enhanced by physical body contact through handshake, hugging, kissing and sex due to close physical contact. Similarly, coronavirus can be released in respiratory droplets through sneezing and coughing. When the respiratory droplets released come in contact with mucous membrane of the eyes, nose and mouth of an individual directly or indirectly through contaminated agents and surfaces (such as Automated Teller Machines and note currencies, electronic gadgets including phones and laptops, door handles and handrails, lift or elevator buttons and fomites including cloths, utensils and furniture), infection may likely occur [22-25].

Transmission can also be airborne as it was recently proven under laboratory condition that respiratory droplets of smaller size which is also called aerosols can remain in air for approximately three hours [26]. Guan and colleagues [27] also showed that this infectious disease can be transmitted in aerosol especially in environment with low air circulation. However, it is still unclear whether the virus remains viable and infectious from the droplets in air more so that there is no documented report of infection from such medium. Still, overcrowding and non-wearing of face mask particularly in hospital environment could be highly compromising and disastrous.

In the same vein, while COVID-19 have been confirmed in stool samples which suggest possible faecal-oral transmission [28,29], WHO-China however reported that faecal-oral transmission is not a feasible mean of COVID-19 transmission [30]. Presence of this COVID-19 virus has also been confirmed in blood [29]. Likewise, viral RNA has been observed to be present in serum [16]. However, transmission through blood is unlikely since respiratory viruses in general are not recognized as being transmitted through blood. Additionally, there are no documented cases of COVID-19 being transmitted through blood. Furthermore, sexual means of transmission is unlikely because there is no substantial proof of the existence of SARS-CoV-2 inside the vaginal swap samples of some selected COVID-19-infected patients [31]. Also, vertical transmission from mother to child has not been documented. Documented reports have shown that fluid from amnion, cord blood, milk from breast-feeding mother and even swabs from neonate's throat were not positive for COVID-19 infection [32].

\section{Risk Factors for COVID-19 Transmission}

Though infection is usually due to exposure to the virus either directly or indirectly, there are some factors that are responsible. These factors may include; a) Human factor such as age, sex, blood group, immunity, personal hygiene, underline pre-existing diseases and travel history to a COVID-19 endemic country b) Environmental factor such as temperature and humidity, and c) Occupations that may predispose some frontline health professional workers to the virus $[16,17,33,34]$.

Though all age groups including infants, children, grown-ups and elderly exposed to the virus are susceptible, patients with lower immune system such as the elderly and those with other underline diseases (immunocompromised) are more prone to developing infections and complications and this may lead to fatality particularly in older ones $[16,17]$. Moreover, Wang and colleagues [35] reported that only few cases of infants and children have been observed. Many other studies have shown that children are less likely at risk of severe COVID-19 infection while few that contracted infection only show mild and moderate infection and symptoms [36-40]. Additionally, with regards to sex, more male have been observed to be infected with COVID-19 compared to their female counterparts [17].

Furthermore, it has been proven that while those who have blood group $\mathrm{O}$ may be protected against severe COVID-19, individuals having blood group $A$ are more susceptible to severe COVID-19 infection [41]. This is as a result of low ACE present on blood group O that can be used by SARS-CoV-2 as a receptor for entry. However, more studies need to be conducted in order to fully establish and validate this report that individuals having blood group A are more prone to risk of acquiring COVID-19, meanwhile people with blood group 0 usually possess a significantly reduced risk of infection compared with non-O blood groups [41]. 
Also, the possibility of vertical transmission of SARSCoV-2 from mother to child has been examined. However, available evidence showed that such means of transmission may not be feasible. This is according to a study in which samples of amniotic fluid, throat swab, vagina secretion, breast milk, cord blood and placenta obtained from some mothers test negative for COVID-19. Also, samples from their neonates which include throat and anal swab, urine, venous blood and sputum all tested negative $[32,42,43]$. This suggests that vertical transmission of SARS-CoV-2 from mother to child is unlikely. A rare case of neonates having COVID-19 was reported and associated with mothers-child close contact after birth [44]. In other studies on COVID-19 among infected neonates, some have attributed neonate's infection to vertical transmission, however when their fetal blood, placenta and amniotic fluid were examined for SARSCoV-2, none were positive of the disease. This showed that such assumption of vertical transmission may be unlikely and baseless at the moment [45-49].

\section{Symptoms of Infection}

COVID-19 can develop into mild and severe infection which may eventually result to death if there is no immediate treatment $[25,50]$. Apparently, coronavirus disease 2019 is usually asymptomatic in the first few days of incubation period and thereafter, symptoms begin to reflect. Some of the major symptoms may vary from mild to serious clinical symptoms which include fever, shortness of breath or dyspnea, dry cough, fatigue, sore throat and sometimes diarrhoea $[7,14,16]$. The incubation time has been documented to be 7 to 14 days [17]. It has also been reported that patients may continue to remain positive of the virus even after symptoms have stopped for up to 8 days [51,52]. Thus, clinicians and policy makers should painstakingly check COVID-19 infected individuals before being discharged. Otherwise, these asymptomatic carrier individuals who interact closely with community members may continue to serve as main reservoir for infection transmission and inadvertently infect others [53]. Similarly, those who may have recovered can further isolate themselves for additional two weeks to ascertain recovery.

\section{Prevention and Control}

While there is currently no commercially available vaccine and drug for treatment of COVID-19, preventive and control strategies can be followed properly to prevent the spread of infection [50]. Some of these preventive and control measure include:

1. Educating and campaigning to community members on the disease cause, transmission, risk factors, symptoms, and the prevention and control of infection. Obviously, there is a general saying that "if one is not informed, one is deformed" and "information and knowledge is power'.

2. High standard of personal hygiene. This involves con- stant hand washing using soap and water for up to 20 seconds particularly after visiting a public place.

3. Physical distancing and proper use of dressing kits especially for frontliners.

4. Immediate contact tracking of suspected individuals and their subsequent isolations.

5. Following government policy on Movement control order and lockdown, that is, stay-at-home order.

6. Quick diagnosis and isolation of positive cases.

7. Self-quarantine up to 14 days after unavoidable travel or return from a journey.

8. Airports and border closure to prevent immigration and emigration which may enhance infection transmission to other states and countries.

9. Adequate confirmation of treated cases before discharge.

10.Avoid stigmatization. Stigmatization could be embarrassing thereby preventing likely infected individuals from showing up for test and subsequent isolation.

11.Eating fruits and vegetables coupled with healthy diet that can boost immunity.

\section{Conclusion}

Conclusively, SARS-CoV-2 is real and its transmission is occurring at an alarming rate particularly from person-to-person through large droplets worldwide. Thus, high level of hygiene and environmental cleanliness should be encouraged and maintained while avoiding all forms of close physical contact including but not limited to sex, hugging, kissing and even hand shaking except among those living together as family or husband and wife. Furthermore, all government policies and instructions guiding COVID-19 control and prevention should be properly followed. Thus, we can have a world-free coronavirus disease in near future.

\section{Limitation}

This minireview is not all inclusive. It includes review of some articles. Further summary should be carried out on other aspect such as treatment of this COVID-19 disease.

\section{References}

1. Carlos WG, Dela Cruz CS, Cao B, Pasnick $S$, Jamil $S$ (2020) Novel Wuhan (2019-nCoV) coronavirus. Am J Respir Crit Care Med 201: 7-8.

2. World Health Organization (2010) What is a pandemic?

3. World Health Organization (2020) Novel coronavirus - China.

4. Coronaviridae Study Group of the International Committee on Taxonomy of Viruses (2020) The species severe acute respiratory syndrome-related coronavirus: Classifying 2019-nCoV and naming it SARS-CoV-2. Nat Microbiol 5: 536-544. 
5. de Groot RJ, Baker SC, Baric R, Enjuanes L, Gorbalenya AE, et al. (2012) Family Coronaviridae. In: King AMQ, Adams MJ, Carstens EB, Lefkowitz EJ, Virus taxonomy. Ninth Report of the International Committee on Taxonomy of $\mathrm{Vi}$ ruses. Elsevier Academic Press, Amsterdam, 806-828.

6. International Committee on Taxonomy of Viruses (2010) ICTV Master Species List 2009. 10.

7. World Health Organization (2020) Novel coronavirus. Situation report - 4 (2019-nCoV) 24 January 2020.

8. Woo PC, Lau SK, Chu CM, Chan KH, Tsoi HW, et al. (2005) Characterization and complete genome sequence of a novel coronavirus, coronavirus HKU1, from patients with pneumonia. J Virol 79: 884-895.

9. Woo PC, Lau SK, Lam CS, Lau CC, Tsang AK, et al. (2012) Discovery of seven novel mammalian and avian coronaviruses in the genus deltacoronavirus supports bat coronaviruses as the gene source of alphacoronavirus and betacoronavirus and avian coronaviruses as the gene source of gammacoronavirus and deltacoronavirus. J Virol 86: 3995-4008.

10. Lau SK, Woo PC, Li KS, Tsang AK, Fan RY, et al. (2015) Discovery of a novel coronavirus, China Rattus coronavirus HKU24, from Norway rats supports the murine origin of Betacoronavirus 1 and has implications for the ancestor of Betacoronavirus lineage A. J Virol 89: 3076-3092.

11. Zhu N, Zhang D, Wang W, Li X, Yang B, et al. (2020) A novel coronavirus from patients with pneumonia in China, 2019. N Engl J Med 382: 727-733.

12. Hui DS, Azhar El, Madani TA, Ntoumi F, Kock R, et al. (2020) The continuing 2019-nCoV epidemic threat of novel coronaviruses to global health-The latest 2019 novel coronavirus outbreak in Wuhan, China. Int J Infect Dis 91: 264266.

13. Hu D, Zhu C, Ai L, He T, Wang Y, et al. (2018) Genomic characterization and infectivity of a novel SARS-like coronavirus in Chinese bats. Emerg Microbes Infect 7: 154.

14. World Health Organization (2020) Coronavirus disease (COVID-19) outbreak.

15. World Health Organization (2020) Coronavirus disease (COVID-19) Pandemic.

16. Huang C, Wang Y, Li X, Ren L, Zhao J, et al. (2020) Clinical features of patients infected with 2019 novel coronavirus in Wuhan, China. Lancet.

17. Li Q, Guan X, Wu P, Wang X, Zhou L, et al. (2020) Early transmission dynamics in Wuhan, China, of novel coronavirus-infected pneumonia. N Engl J Med 382: 1199-1207.

18. Jin YH, Cai L, Cheng ZS, Cheng H, Deng T, et al. (2020) A rapid advice guideline for the diagnosis and treatment of 2019 novel coronavirus (2019-nCoV) infected pneumonia (standard version). Mil Med Res 7: 4.

19. Chan JF, Yuan S, Kok KH, To KK, Chu H, et al. (2020) A familial cluster of pneumonia associated with the 2019 novel coronavirus indicating person-to-person transmission: A study of a family cluster. Lancet 395: 514-523.

20. Chen N, Zhou M, Dong X, Qu J, Gong F, et al. (2020) Epidemiological and clinical characteristics of 99 cases of 2019 novel coronavirus pneumonia in Wuhan, China: A descriptive study. Lancet 395: 507-513.

21. Wang D, Hu B, Hu C, Zhu F, Liu X, et al. (2020) Clinical characteristics of 138 hospitalized patients with 2019 novel coronavirus-infected pneumonia in Wuhan, China. JAMA.
22. Lu C-w, Liu X-f, Jia Z-f (2020) 2019-nCoV transmission through the ocular surface must not be ignored. Lancet 395: e39.

23. National Health Commission of China (2020) New coronavirus pneumonia prevention and control program (6th edn).

24. Ong SWX, Tan YK, Chia PY, Lee TH, Ng OT, et al. (2020) Air, surface environmental, and personal protective equipment contamination by severe acute respiratory syndrome coronavirus 2 (SARS-CoV-2) from a symptomatic patient. JAMA 323: 1610-1612.

25. Centers for Disease Control and Prevention (2020) Interim clinical guidance for management of patients with confirmed 2019 novel coronavirus (2019-nCoV) infection.

26. van Doremalen N, Bushmaker T, Morris DH, Holbrook MG, Gamble A, et al. (2020) Aerosol and Surface Stability of SARS-CoV-2 as Compared with SARS-CoV-1. N Engl J Med 382: 1564-1567.

27. Guan W-j, Ni Z-y, Hu Y, Liang W-h, Ou C-q, et al. (2020) Clinical characteristics of 2019 novel coronavirus infection in China. medRxiv.

28. Tang A, Tong ZD, Wang HL, Dai YX, Li KF, et al. (2020) Detection of novel coronavirus by RT-PCR in stool specimen from asymptomatic child, China. Emerg Infect Dis 26: 1337-1339.

29. Zhang W, Du RH, Li B, Zheng X-S, Yang X-L, et al. (2020) Molecular and serological investigation of 2019-nCoV infected patients: Implication of multiple shedding routes. Emerg Microbes Infect 9: 386-389.

30. (2020) Report of the WHO-China Joint Mission on Coronavirus Disease 2019 (COVID-2019).

31. Lin Qiu, Xia Liu, Meng Xiao, Jing Xie, Wei Cao, et al. (2020) SARS-CoV-2 is not detectable in the vaginal fluid of women with severe COVID-19 infection. Clin Infect Dis.

32. Chen H, Guo J, Wang C, Luo F, Yu X, et al. (2020) Clinical characteristics and intrauterine vertical transmission potential of COVID-19 infection in nine pregnant women: A retrospective review of medical records. Lancet 395: 809-815.

33. Liu T, Hu J, Kang M, Lin L, Zhong H, et al. (2020) Transmission dynamics of 2019 novel coronavirus (2019-nCoV).

34. Gralinski LE, Menachery VD (2020) Return of the coronavirus: 2019-nCoV. Viruses 12: 135.

35. Wang D, Ju XL, Xie F, Lu Y, Li FY, et al. (2020) Clinical analysis of 31 cases of 2019 novel coronavirus infection in children from six provinces (autonomous region) of northern China. Zhonghua Er Ke Za Zhi 58: 269-274.

36. Liu H, Liu F, Li J, Zhang T, Wang D, et al. (2020) Clinical and CT imaging features of the COVID-19 pneumonia: Focus on pregnant women and children. J Inf Secur 80: e7-e13.

37. Lu X, Zhang L, Du H, Zhang J, Li YY, et al. (2020) SARSCoV-2 infection in children. N Engl J Med 382: 1663-1665.

38. Ji L-N, Chao S, Wang Y-J, Li XJ, Mu XD, et al. (2020) Clinical features of pediatric patients with COVID-19: A report of two family cluster cases. World J Pediatr 16: 267-270.

39. Xu Y, Li X, Zhu B, Liang H, Fang C, et al. (2020) Characteristics of pediatric SARS-CoV-2 infection and potential evidence for persistent fecal viral shedding. Nat Med 26: 502-505.

40. Cai J, Xu J, Lin D, Yang Z, Xu L, et al. (2020) A case series of children with 2019 novel coronavirus infection: Clinical and epidemiological features. Clin Infect Dis. 
41. Zhao J, Yuan Q, Wang H, Liu W, Liao X, et al. (2020) Antibody responses to SARS-CoV-2 in patients of novel coronavirus disease 2019. Clin Infect Dis, ciaa344.

42. Peng Z, Wang J, Mo Y, Duan W, Xiang G, et al. (2020) Unlikely SARS-CoV-2 vertical transmission from mother to child: A case report. J Infect Public Health 13: 818-820.

43. Zhu H, Wang L, Fang C, Peng S, Zhang L, et al. (2020) Clinical analysis of 10 neonates born to mothers with 2019nCoV penumonia. Transl Pediatr 9: 51-60.

44. Schwartz David A (2020) An analysis of 38 pregnant women with COVID-19, their newborn infants, and maternal-fetal transmission of sars-cov-2: Maternal coronavirus infections and pregnancy outcomes. Arch Pathol Lab Med.

45. Khan S, Jun L, Nawsherwan, Siddique R, Li Y, et al. (2020) Association of COVID-19 with pregnancy outcomes in health-care workers and general women. Clin Microbiol Infect 26: 788-790.

46. Zeng L, Xia S, Yuan W, Yan K, Xiao F, et al. (2020) Neonatal early-onset infection with SARS-CoV-2 in 33 neonates born to mothers with COVID-19 in Wuhan, China. JAMA Pediatr 26: 722-725.
47. Zeng $H$, Xu C, Fan J, Tang Y, Deng Q, et al. (2020) Antibodies in infants born to mothers with COVID-19 pneumonia. JAMA 323: 1848-1849.

48. Dong L, Tian J, He S, Zhu C, Wang J, et al. (2020) Possible vertical transmission of SARS-CoV-2 from an infected mother to her newborn. JAMA 323: 1846-1848.

49. Alzamora MC, Paredes T, Caceres D, Webb CM, Valdez LM, et al. (2020) Severe COVID-19 during pregnancy and possible vertical transmission. Am J Perinatol 37: 861-865.

50. CDC (2020) Novel coronavirus, Wuhan, China.

51. Rothe C, Schunk M, Sothmann P, Bretzel G, Froeschl G, et al. (2020) Transmission of 2019-ncov infection from an asymptomatic contact in Germany. N Engl J Med 382: 970971.

52. Young BE, Ong SWX, Kalimuddin S, Low JG, Tan SY, et al. (2020) Epidemiologic features and clinical course of patients infected with SARS-CoV-2 in Singapore. JAMA 323: 1488-1494.

53. Bai Y, Yao L, Wei T, Tian F, Jin DY, et al. (2020) Presumed asymptomatic carrier transmission of COVID-19. JAMA 323: 1406-1407. 